\title{
Comparison of Physical Structure of Iran Traditional Neighborhoods Based on Living Center Theory of Christopher Alexander (Case Study: Haji and Kolapa Neighborhoods in Hamedan)
}

\author{
Somayeh Hatefi Shojae ${ }^{1}$ \\ ${ }^{1}$ Young Researchers and Elites club, Science and Research Branch, Islamic Azad University, Tehran, Iran \\ Correspondence: Somayeh Hatefi Shogae, Master Student of Architecture, Young Researchers and Elites club, \\ Science and Research Branch, Islamic Azad University, Tehran, Iran. E-mail: somayeh.hatefishogae@srbiau.ac.ir
}

Received: November 11, 2015

Accepted: December 14, 2015 Online Published: February 2, 2016

doi:10.5539/mas.v10n4p101

URL: http://dx.doi.org/10.5539/mas.v10n4p101

\begin{abstract}
In the way Christopher Alexander ${ }^{1}$ provides understanding and knowing order of nature, the pattern of living structures according to the concepts of totality and strong centers are paid attention to in 15 integrated features. The purpose of this paper is to analyze the physical totality of these two neighborhoods based on Alexander's living center theory and its adaptability with architectural physics. This paper tries to answer following questions: What is the theory of living centers proposed by Alexander? Based on living center theory, how is the geometrical structure of traditional neighborhoods in Hamedan? How is the comparative study of structure of both neighborhoods based on Alexander's theory? The results of study suggest that certain space as an essential feature of the theory of Alexander is not applicable with geometry structure of elements of the traditional neighborhoods of Hamadan. Comparison of geometry structure of the neighborhood and the characters of Alexander's theory pattern suggests that the most important role in the neighborhood for creating more life arises from strong centers, levels of Scale, boundaries, non-separateness, roughness, the void and contrast.The findings survey can use urban planners, urban designers and architectures to design new neighborhoods.
\end{abstract}

Keywords: neighborhood, neighborhood of Hamadan, Haji and Kolapa, life, strong center

\section{Introduction}

Change and crisis in different economic, social and physical dimensions of cities bring about remarkable negative effects on cities and in particular the neighborhoods which reduce the urban neighborhood quality and make loss of totality. Therefore, it is necessary to pay attention to creation of living urban spaces with an integrated totality in architecture and urbanization. Based on behavioral patterns, Alexander proposed order and deep geometrical relations in nature with the concept of life phenomenon and living structures believing that strong centers and integrated totality can help to realize the internal energy of beings to be enlived. (Alexander, 2002). Traditional neighborhoods of Hamedan were formed in Qajar and Safavid era with different elements such as mosque, bath and square. Haji and Colapa are the traditional neighborhoods the ancient texture of which has been preserved.The purpose of this paper is to analyze the physical totality of these two neighborhoods based on Alexander's living center theory and its adaptability with architectural physics. The questions of this paper are: What is Alexander's living center theory? How is the comparative study of both neighborhood structures based on Alexander's theory? The paper proceeds to show that living center theory cannot be applied to the structure of traditional neighborhoods. Also, Haji neighborhood has more living centers than Colapa neighborhood.

\subsection{Material and Methods}

This study is carried out in a descriptive-analytic method based on a quality approach in which the data are collected from library and field observation.

\subsection{Literature Review}

Research on traditional neighborhoods has been studied from different views by researchers including the latest models of patterning and renewal of framework of quarters by Mohsen Habibi (2003), the capacity of the neighborhood growth of the urban development by: Mojtaba Rafeian (2010), public participation in neighborhood organization and development; Marjan Sharafi (2009). Haji district in a paper entitled group 
belonging to the place, the fulfillment of social housing in traditional neighborhoods was studied by Hasan Sajjadzadeh (2011). Architecture from Alexander's view recognizing the ability of feeling to create a living architecture (Rahmani, 2013). Mohajery analyzes the design ideas by Alexander from the book notes on the composition of form to nature of order (new concepts of complexity theory. He believes Alexander's theory could establish a relationship between different parts of design and planning (Mohajery, 2008). Sabry and Akbari points out that Alexander started his work criticizing the modern world and scientific worldview and thought of architecture related to worldview. Relying on the nature and tradition system, he asked for termination of destruction through the modern urbanization (Sabry \& Akbari, 2013). Hedayat nia introduces fifteen features of Alexander's theory for Ghourtan castle and concludes that the architecture of desert in Iran matches the criteria of Alexander's (Hedayat, 2013). Life phenomenon and living structures pattern in traditional neighborhoods as an urban space in local scale is a new issue that has not been studied before.

\section{Theoretical Principles Research}

\subsection{Explaining the Alexander's Theory}

A key concept in Alexander's theory is that order is a dynamic concept rather than a static one. Although humans often experience a large number of components or relationships as complexity, multiplicity does not disorder (Alexander, 2010). Through his writings about architecture, Alexander also refers to philosophy of life and nature. He believes that there is a deep connection between nature and human's mind. He sees the world as an integrated and ordered generic which contains living and non-living creatures (Alexander, ibid).The idea of order indicates that all beings can be divided into living and non-living structures (Alexander, 2002). The important concepts for Alexander's theory are life, integrated totality strong centers and pattern of living structures which are to be briefly explained in order to survey and analyze different options.

\subsubsection{Life}

Alexander defines life as it is manifest in physical architecture, its measurable characteristics, and the stepwise transformations that make up any process that is capable of producing a living structure (Alexander, 2010). Alexander focuses the phenomenon of life and defines it as a quality existing in the nature of space and everything such as functional spaces of living system. Life is general concept exists in every area of contiguous space in geometric, structural, social or formal aspect (Alexander, 2002).

\subsubsection{Integrated Wholeness}

Alexander's conception of wholeness and centers is grounded in the geometry of space and its physical attributes of position and distance. To apply Alexander's concepts of physical structure to information systems, they must first be translated from a language of physical space to a language of cognitive space where physical position and distance correspond to concepts and consonance in "fields" populated by abstractions rather than shapes (Alexander, 2010). Each spatial structure consists of integrated system shaping the ground of geometrical relationships and complex structures along with human activities and events associating it (Alexander, 2010). Alexander believes life as a subtle structure containing different parts the life of spaces comes from this totality in a way that supporting the life comes from this reality that thing acts as an integrated totality which means that we see it as a part of continuous chain (Alexander, ibid).

\subsubsection{Strong Center}

Strong center is a structured field through the space which includes separated set of points in space which represents a kind of centralization due to its structure which is caused by internal coherence and its connections to the context it is present at (Alexander, ibid).There are found patterns in the universe their interaction causes the world to become balanced and compensate the destructive forces in the nature (Tahouri, 2002).

\subsubsection{Patterns of Living Structures}

Integrated totality containing powerful centers and life makes patterns of living structures.For Alexander,the presence of these living structures in creation process is so important that the city or building can be evaluated based on the presence or absence of these patterns. He focuses the experimental methods to understand these living structures although expressed in mathematics language (mohajery et al., 2008).

\subsection{Alexander's Theory is based on 15 Underlying Features as Summarized Below}

\subsubsection{Levels of Scale}

Places where levels of scale big, small and very small are shaped in a beautiful spectrum with bounded levels make a deeper sense of levels and centers are created according to them (Alexander, 2002). 


\subsubsection{Strong Centers}

The most important feature of a living creature based of which totalities are shaped is the existence of strong centers presented as totality's pillars. Centers can be various and symmetric since each center is represented as a square which is beyond a local symmetry. By strong centers we do not necessarily mean geometric centers because if a center is single dimensional which is only appeared as geometric shape not a strong center, it makes a poor power (Alexander, ibid).

\subsubsection{Boundaries}

Living centers are shaped by boundaries. The aim of creating a round boundaries is a dual aim. boundaries act for separating and linking, boundaries makes attention for the center and on the other hand the limited center is integrated by linking to the beyond world (Alexander, ibid).

\subsubsection{Alternating Repetition}

One way for center to support its life is alternating repetition by which we mean a kind of repeated tone parallel and alternating which are intensified through primary centers' rhythm (Alexander, ibid).

\subsubsection{Positive Space}

The most simple and necessary feature through living structures is certain space which is Prominence of each particle to the outside. If he center is certain and well formed the certain space helps it being more powerful (Alexander, ibid).

\subsubsection{Good Shape}

The feature good shape is dependent to centers each part of which has a certain and defined form. In order to have a good form, all forms have to be definite after Analysis and characterization (Alexander, ibid).

\subsubsection{Local Symmetries}

There is a bilateral relationship between local symmetry and living center. Local and general symmetry Supplements for sustaining a totality. In one hand the most continuous and coherent patterns have the most local symmetry and on the other hand symmetric parts are necessary in order to change a plan to a totality. Generally, it is concluded that local symmetry should rule on total structure in order to create strong centers however in formation of a coherent space, general symmetry helps all parts' understanding of the space (Alexander, ibid).

\subsubsection{Deep Interlock and Ambiguity}

Connection of centers and difficulty of separating them from the adjunct centers make a deep solidarity between them. Ambiguity and Solidarity appear as Inter connectedness and being band with the near centers and also as creating an important point which belongs to its own center and also to around centers (Alexander, ibid).

\subsubsection{Contrast}

Contrast $t$ in living creature causes its stability and it can be created as different shapes of full and empty, white and black and etc. The important point of creating such centers is Integration and cohesion of the spaces which should be protected (Alexander, ibid).

\subsubsection{Gradients}

Moving through the space and hierarchy with gradual change of distance, size, intensity and features make a proper ground for creation of strong centers. Hierarchy makes variety of centers and reveals its internal totality (Alexander, ibid).

\subsubsection{Roughness}

Roughness is fulfilled when uniform designs are not located in same place. The important point of creating a Heterogenic space is the designer to be Unconscious and unintended to create strong centers (Alexander, ibid).

\subsubsection{Echoes}

Echo appears when smaller elements and centers which make bigger centers are formally members of a family and this cause their Coherence and unity (Alexander, ibid).

\subsubsection{The Void}

Another element effective in formation of living centers is the empty space between them. Accordingly in addition to peace and silence made by empty space, it attracts more energy of center and empowers it and forms a geometric and regular space (Alexander, ibid). 


\subsubsection{Simplicity and Inner Calm}

Totality of a living structure is simple so that in most times it can be created through simple and geometric forms. However internal simplicity and relax is not only made apparently rather it is reached by protecting necessary elemtns and omitting the others (Alexander, ibid, 226-229)

\subsubsection{Not-Separateness}

The last and also the most important feature is integrality which is fulfilled as appearance of a living generic as part in the world and inseparable from it so that it is melted is around context (Alexander, ibid, 230-235).

\section{Case Study Area}

\section{Hamadan History}

The concept of city: "city in ancient Persian was called "Kheshtar" meaning kingdom ". Also, this term in Avesta is called as "Kheshtareh" The Persian word" city "has come from this Avestan term, while in Sanskrit the word was called "Keshtar" In Sassanian era "city" was called in modern concept. "State", or province is the second component of city, coming from Old Persian and Avestan word "Astan" to mean a place (Qadakchy, 2008).The destruction of the neighborhoods of Hamadan, and the physical texture changing began in Reza Shah era.In this period between 1932 to 1937 the central square of the city was made by German Karl Frisch with pre-planned radial design, and six streets radiating from it interrupted the spine, alleys and old markets and paved the way for Western culture (ibid, 2008). Many cities have been created by emerging numbers of villages. Hamadan is perhaps the best known example. In the surrounding neighborhoods at first were villages which had been agricultural centers, and with the expansion of neighborhoods these centers were formed among neighborhoods. Some of the gardens and agricultural centers were in area of city which include Mir Aqeel garden around the dome Alavian, Nazar Beyg garden in Nazar Beyg neighborhood, Kolapa garden inside Kolapa area and some others. The structure of neighborhood was in a manner that the streets were isolated from a great area called grass with many twists and turns so that only the local people knew them and, at times, crossed dark roofed transits. Houses were around these passages and lords' houses were at the end twists with high walls were hidden from the view of passers. Therefore, the neighborhoods were independent units of city, including mosques, baths, aqueducts and multidisciplinary malls or residential areas (ibid, 2008).

\subsection{The Introduction of the Samples}

Haji neighborhood with residential use is intermediate between shohada and Shewerin Street and has area named as the lawn Haji. This neighborhood is attributed to Mr. Mohammad Ismail Isfahani. In the second half of the thirteenth century AH, 120-130 years ago, this tribe came from Isfahan to Hamadan and called the neighborhood after their own name; their descendants and their relatives lived in the same place and the traces of their life were remained until 40-50 years ago (AZkaei). This neighborhood is one of the most vibrant neighborhoods while the centre of area is created by combining the two rectangle and triangle-shaped spaces.the communication roads are led from the center to different parts of neighborhood, downtown and other neighborhoods, Green trees, water, mosques, schools, male and female bathrooms, café and infirmary and large shop have given special effects to this small square (Biglari, 1977).

Kolapa neighborhood with residential use is in East side of Booali St. located between Ayatollah Taleghani Street and Ayatollah Madani Boulevard. According to doctor Azkaei appellation of the neighborhood is not clear and the words can be meant small foot (AZkaei). Neighborhood center form is like a small-square and its nearby space is occupied by mosque, grocery, school, bakery, butchery, demolished baths and blocked fountains. The grass also has endowed a special beauty to the neighborhood.. In south and southwest of the neighborhood three uses are located: Bu Ali hotel, the Islamic Revolution Court and the Ekbatan Hospital (Consulting Engineers, 1993). 


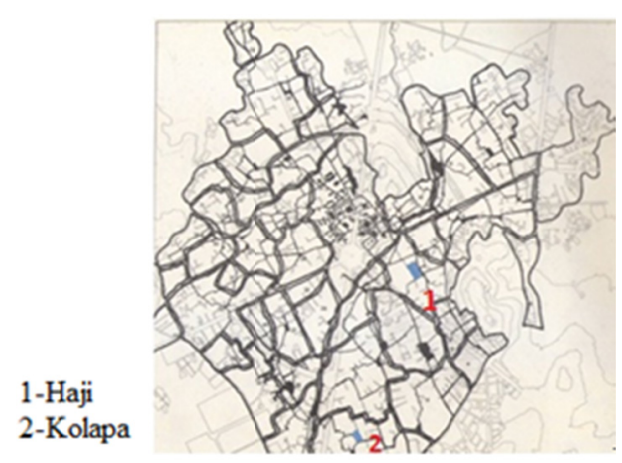

Figure 1. Haji and Kolapa neighborhood location on a map dividing Hamadan neighborhoods

\section{Analysis}

The structure of traditional neighborhoods is analyzed regarding 15 features of Alexander's theory.

\subsection{Levels of Scale}

Life in neighborhoods flows with shopping malls, mosques, grass and... with levels of scale, certain mutation, logical relationship fitted with their scales in location of larger and smaller centers.

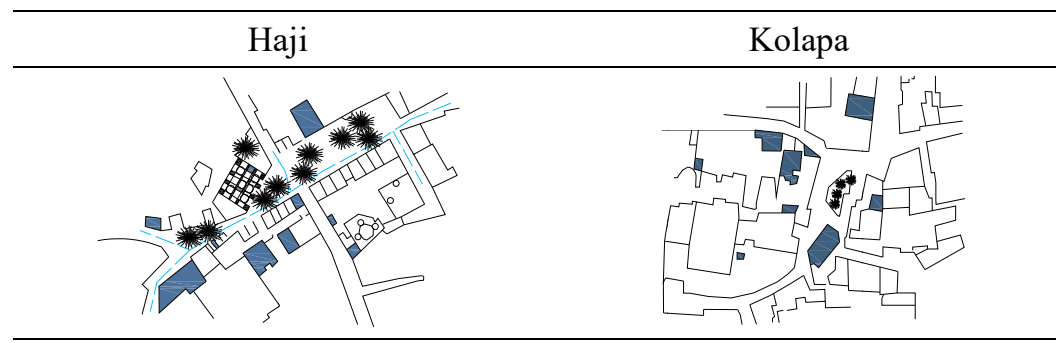

Figure 2. Analysis of levels of scale in typical neighborhood of Hamadan

Source: Consulting Engineers1993, author's analysis.

\subsection{Strong Centers}

The most important feature of the living quarters is having a whole variety of different levels as strong centers. Analysis of two neighborhoods in Figure 3 clearly shows how the centers are formed in the center of neighborhoods like small mall, mosques, baths, banks, aqueduct and the grass. The shape is not symmetrical in the sense of a centerfield neighborhood, and although the empty space of neighborhood center is formed in organic, amorphous and chaotic way, it is considered as a strong center, The structure of neighborhoods shows a sense of centralization which guides the person with a layered system of nested spheres one after another in the neighborhood to the neighborhood center to heart as the center of the neighborhood as a group space. Figure 3 shos how centers such as mosque, bath, bank, and the lawn act as a square although they are not shaped symmetrically.

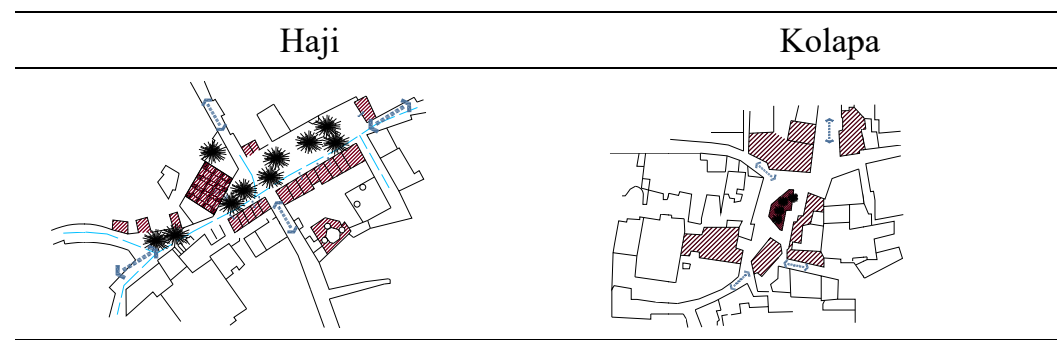

Figure 3. Analysis of strong centers in typical neighborhoods of Hamadan

Source: Consulting Engineers, 1993, author's analysis. 


\subsection{Boundaries}

Living centers in neighborhoods that are symbolized by the boundaries of vernacular architecture are formed in all dimensions with different layers, narrow passages and arches of the mud wall and are all to protect lively space in creating a neighborhood centers, and each has its boders.

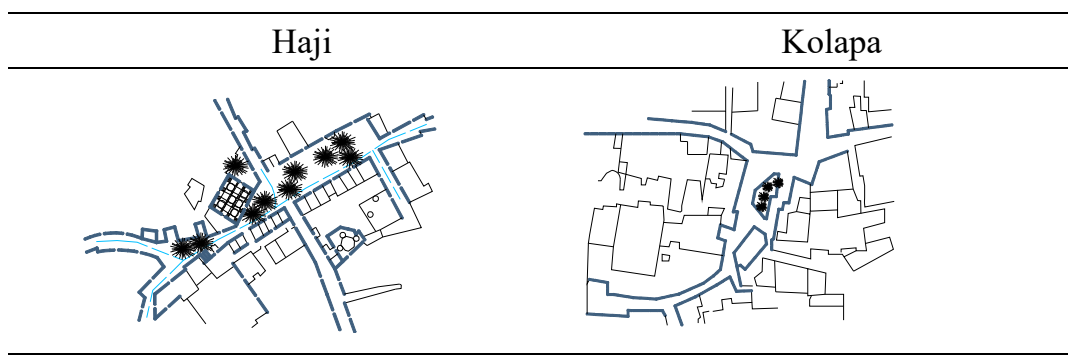

Figure4. Analysis of boundaries in typical neighborhood of Hamadan

Source: Consulting Engineers, 1993, author's analysis.

\subsection{Alternating Repetition}

In Haji neighborhood centers, repetitive centers within a whole in parallel with the alternating rhythm with the second center are interlocked and intertwining, but iterative structure in the Kolapa neighborhood tends to be inexact and diverse, with this difference and variety, creating a beautiful oscillation.

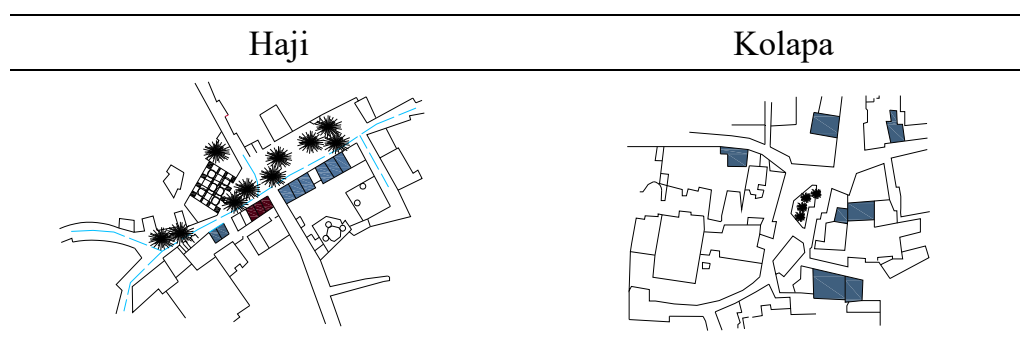

Figure 5. Analysis of alternating repetition in typical neighborhood of Hamadan

Source: Consulting Engineers, 1993, author's analysis.

\subsection{Positive Space}

To the extent any space is consisted of simple parts, and their spaces form well-defined areas,they will be more lively (Alexander, ibid). But neighborhood center in both samples ensures with indefinite form, a strong center for each part of space which as a social and public open space is full of meaning and purpose free from irrelevancy.

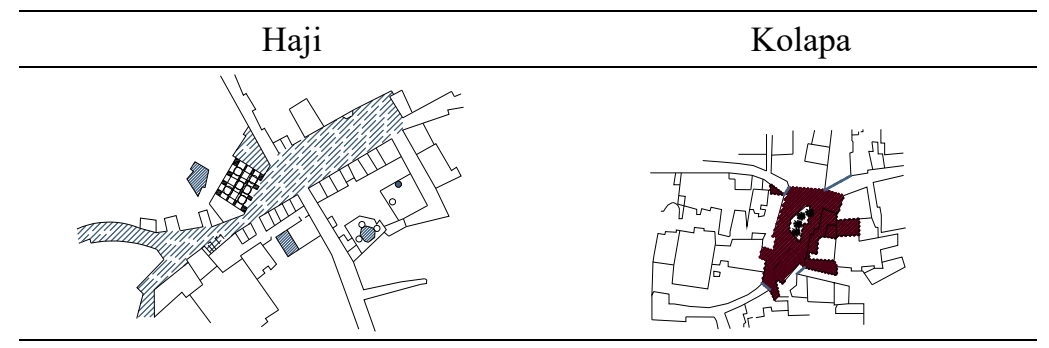

$\overline{\text { Figure 6. Analysis of positive space in typical neighborhood of Hamadan }}$

Source: Consulting Engineers, 1993, author's analysis. 


\subsection{Good Shape}

Elements of Haji neighborhood center which are made of consistent and simplest forms, elementary and novel, have beautiful shape. In contrast, neighborhood center which is made of strong elements, because of its noncentrality inside itself has a bad shape and although it hasn't an inner symmetry or two- side symmetry ; spaces have been created around it which are clear, consistent, and compact, with a sense of maturity and enclosure.

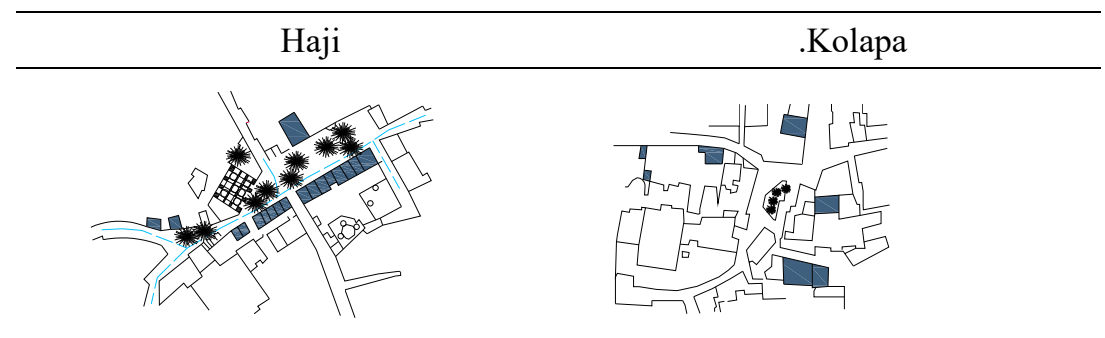

Figure 7. Analysis of good shape in typical neighborhood of Hamadan

Source: Consulting Engineers, 1993, author's analysis.

\subsection{Local Symmetres}

Local symmetry should be dominant in the total structure of neighborhood to create strong centers, and in formation of coherent space. Global symmetry of the single space helps the observer to understand the space better, but in each of two neighborhoods, centers can be seen including mosques, marketplaces and grass that have local symmetry.

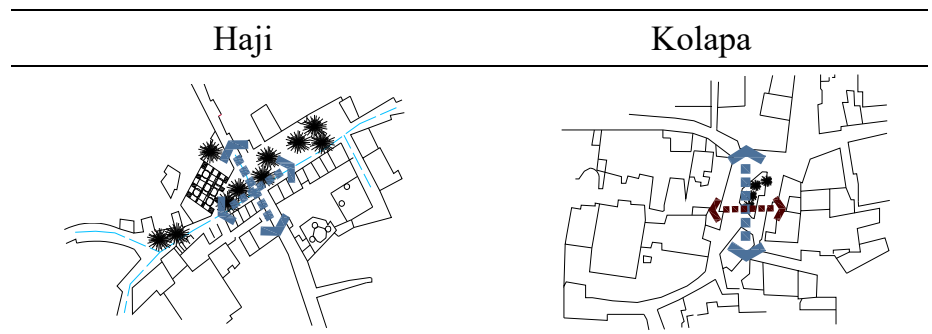

Figure 8. Analysis of local symmetry in a typical neighborhood of Hamadan

Source: Consulting Engineers, 1993, author's analysis.

\subsection{Deep Interlock and Ambiguity}

Roofed narrow passes with lots of twists and turns in neighborhoods are as bridge that at the same time belong to the neighborhood and the surrounding areas, and both are connected to the irrefrangible node.

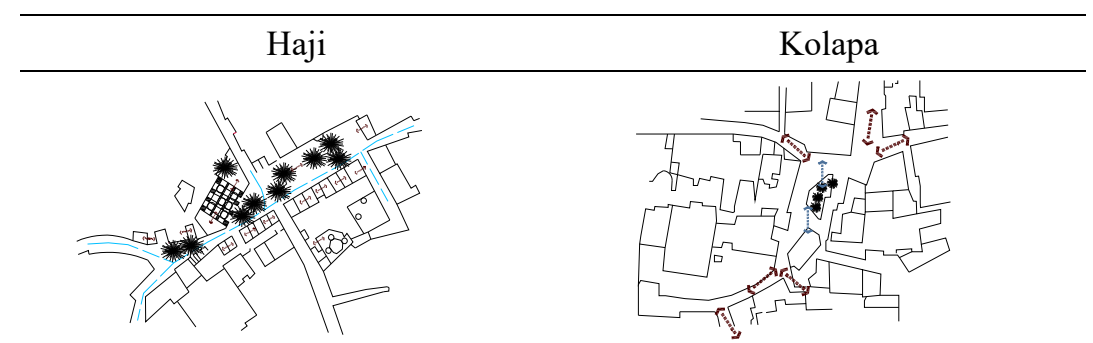

Figure 9. Analysis of deep interlock and ambiguity in typical neighborhoods inHamedan

Source: Consulting Engineers, 1993, author's analysis. 


\subsection{Contrast}

Life in neighborhood can not occur without difference and diversity and the most popular contrast that creates life is full and empty space, moving space and pause space. In practical situations, various residential areas, commercial (market), religious (mosques), social (grass) work better together, and these differences will allow centers to get their pleasant nature.

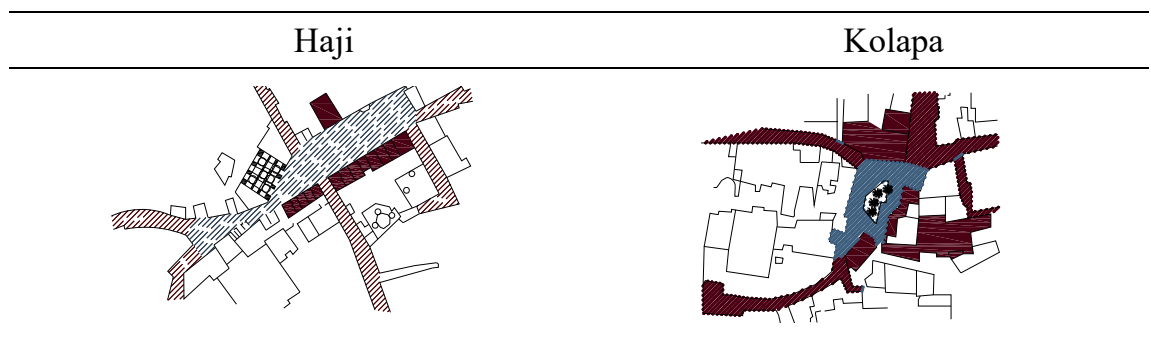

Figure 10. Analysis of contrast in typical neighborhoods of Hamedan

Source: Consulting Engineers, 1993, author's analysis.

\subsection{Gradients}

Quality changes gradually, gently and delicately from one extreme to another in neighborhood spaces, including lawns with cultural function, houses with residential function, mosques with religious functions and malls with economic function.

\subsection{Roughness}

As in the structure of the neighborhood size and location of such spaces have made the most beautiful and most appropriate spaces, it has caused heterogeneity. Furthermore, the heterogeneity seen in the neighborhood elements can be seen in original form of neighborhood.

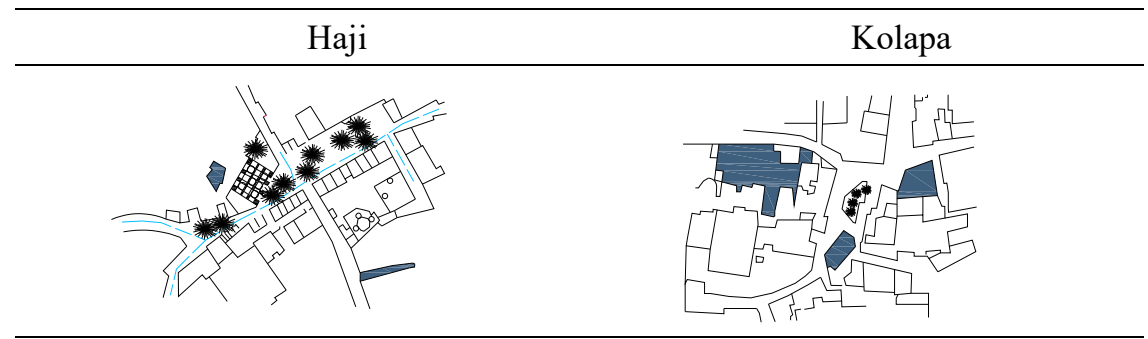

Figure 11. Analysis of roughness in typical neighborhoods of Hamedan

Source: Consulting Engineers, 1993, author's analysis.

\subsection{Echoes}

Regarding structure of neighborhood, heterogeneity in neighborhoods is seen more than reflection, and few places have been created with this template. 


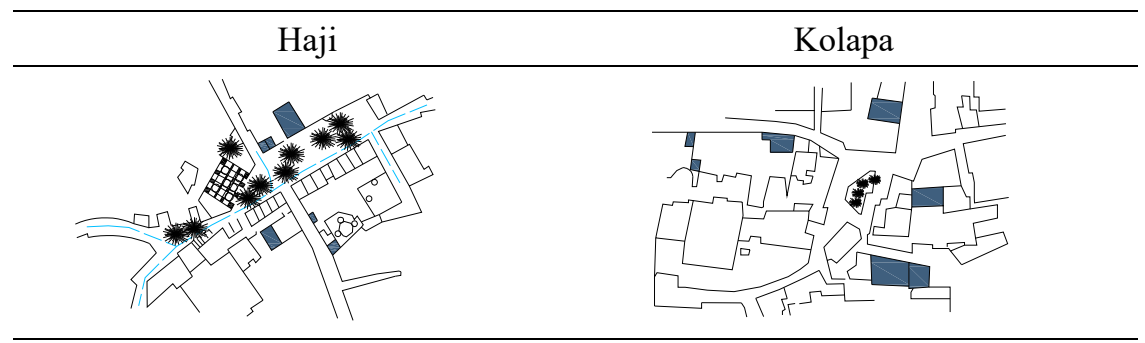

Figure 12. Analysis of echoes in typical neighborhoods of Hamedan

Source: Consulting Engineers, 1993, author's analysis.

\subsection{The Void}

The empty space in the neighborhood center brings about peace and quiet in the heart of the space, through which a major hub gives life for smaller centers.

Haji Kolapa

Figure 13. Analysis of the the void in typical neighborhoods of Hamedan

Resource: Consulting Engineers, 1993, author's analysis.

\subsection{Simplicity and Inner Calm}

Simplicity and inner calm is quality that is necessary in completion of a "whole" of the elements of the neighborhood in contrast, relaxation is relevant with slowness, superiority, peace and quiet in the neighborhood is often associated with non-geometric forms.

\subsection{Not-Separateness}

Neighborhood is intermingled harmoniously and humbly in its surroundings and the most important element is the center of the neighborhood as a consistent center for being connected with what is around and there is no separation between them.

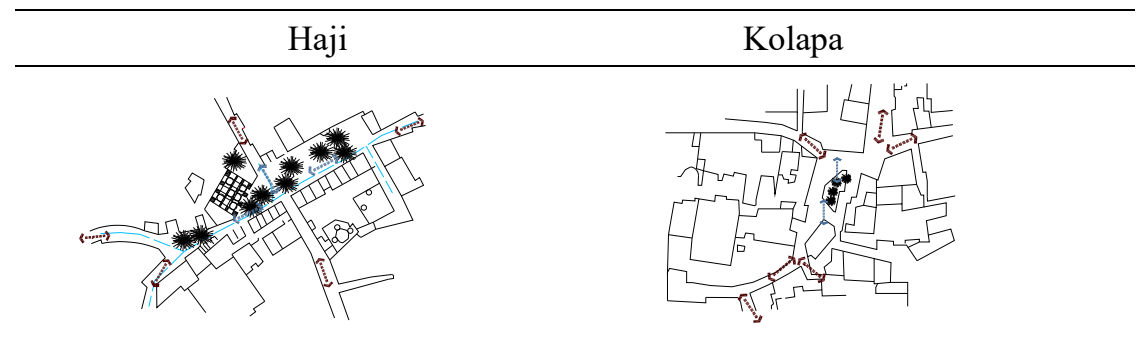

Figure 14. Analysis of not-separation in typical neighborhoods of Hamedan

Source: Consulting Engineers, 1993, author's analysis.

\section{Discussion}

What comes next is the result of studies, surveys and analysis of comparison between neighborhood of Hamadan concept and Alexander's Theory. It is explained at table 1: 
Table 1. Comparative analysis of the theory of Alexander and the representative structure neighborhood of Hamadan

\begin{tabular}{lll}
\hline \multicolumn{2}{l}{ Comparative analysis of the theory of Alexander and neighborhood of Hamadan } \\
\hline Alexander's Theory & \multicolumn{2}{l}{ neighborhood of Hamadan } \\
\cline { 2 - 3 } & $* *$ & Kolapa \\
\hline Levels of scale & $* *$ & $*$ \\
Strong centers & $* *$ & $*$ \\
Boundaries & $*$ & $*$ \\
Alternating repetition & $* *$ & $*$ \\
Positive space & $* *$ & $*$ \\
Good shape & $*$ & $*$ \\
Local symmetry & $*$ & $*$ \\
Deep Interlock and Ambiguity & $* *$ & $*$ \\
contrast & $*$ & $*$ \\
Gradients & $*$ & $* *$ \\
Roughness & $* *$ & $*$ \\
Echoes & $*$ & $*$ \\
The void & $*$ & $*$ \\
Simplicity and Inner calm & $* *$ & $* *$ \\
Not-separateness & & \\
\end{tabular}

\section{Conclusion}

Life space is originated from an integrated whole that is the result of a strong center and this means that we see it extended as a part of a continuous chain. According to Christopher Alexander, life phenomenon is formed geometrically in space from 15 characters which can be seen in living and non-living structures.According to studies on the traditional neighborhoods of Haji and Kolapa in Hamadan, we can express geometric structure of space based on theory of Alexander does not comply fully with the phenomenon of life in the traditional neighborhood because structures of traditional neighborhoods is based on local and organic patterns and certain spaces of the neighborhood play a less important role. In theory of Alexander, positive space has important role in making space live but neighborhood center as an important and integral member of the neighborhood, although without having good shape. Haji neighborhood with the greatest number of characters in the theory of Alexander has more life originated from strong centers in the neighborhood center like aqueduct and baths. As a public space and second character, the existence of more contrast among functions of its elements, and other character the positive space in neighborhood center elements including shops, bath, and mosque take place. three important elements in Kolapa neighborhood including hotels, university and hospital due to their location have no role in creating life in neighborhood center.Due to comparison of geometry structures of the neighborhoods and features of Alexander's living structures pattern, it seems most important role in studied neighborhoods for creating more life arises from strong centers, Levels of scale, Boundaries, Not-separateness, Roughness, The void and Contrast.

\section{Footnote}

Christopher Alexandre was born in Vienna, Austria, in 1936 and grew up in England. He obtained his bachelor degree in architecture and master degree in mathematics from Cambridge university.Alexandre got his Ph.D in architecture from Havard in 1963 and became the lecturer in berkley univercity of cALIFORNIA from 1963.He is the forefather of pattern language movement in computer science and the author of pattern language in 1977.

\section{References}

Alexander, Ch. (2002). The Nature of Order: An Essay on the Art of Building and the Nature of the Universe. Publisher: Center for Environmental Structure. By: Cyrus Sabri, R. Akbari, Ali. Tehran, Parham Naghsh.

Alexander, Ch. (2010). Nature of Order. Thriving Systems Theory and Metaphor-Driven Modeling. Retrieved from http://link.springer.com/chapter/10.1007\%2F978-1-84996-302-2_2

Ardalan, N. (1969). A comprehensive plan of Bu-Ali Sina University. Hamedan, Kandelys consultant.

Biglari, E. (1977). The markets of Iran. Hamedan. Publication of Hamdami Bonyad.

Habibi, M. (2003). How patterning models \& renewal of neighborhood framework. Honar-Ha-ye-Ziba journal, 
13(13), 32-39. Retrieved from https://jhz.ut.ac.ir/article_10657_1070.html

Hedayat, M. R. (2013). Assessment of physical and spatial features of ghortan castle based on alexander's ideas.Master's thesis, art university, Isfahan.

Mohajery, N., \& Qumi, Sh. (2008). An analytical approach to design theories of Christopher Alexander. Hoviatshhr, 2, 45-56. Retrieved from http://hoviatshahr.srbiau.ac.ir/article_1084_252.html

Pir babaie, M. T., \& Sajadzadeh, H. (2011). Group belonging to the place, the fulfillment of social housing in traditional neighborhoods. Bagh-e -Nazar, 8(16), 17-28. Retrieved from http://www.bagh-sj.com/article_2_1.html

Qadakchy, I. (2008). An introduction to the history of neighborhoods. Journal of culture and people, 2, 26. Retrieved from http://www.maaref.ir/magtoc.asp?mgID=3009\&Number=26\&Appendix $=0$

Rafeian, M., Taghvaei, A., \& Vahdani, H. (2010). CAPACITY ASSESSMENT FOR COMMUNITY DEVELOPMENT. Sofeh journal, 19(49), 93-104. Retrieved from http://scj.sbu.ac.ir/index.php/SOFEH/article/view/1713

Rahmani, M. (2013). recognizing the ability of feeling to create a living architecture based on Christopher Alexander`s ideas. Sofeh., 62. Retrieved from http://scj.sbu.ac.ir/index.php/SOFEH/article/view/6786

RezaZadeh, R., \& Selseleh, A. (2010). A review of sustainable community development policies through an assetbased approach, with emphasis on social \& physical capital. Journal of Architecture and Urbn planing, 2(4), 121-139. Retrieved from http://en.journals.sid.ir/ViewPaper.aspx?ID=253881

Sabry, S. R., \& Akbari, A. (2013). The concept of order Christpher Alexander and new science. Sofeh., 61, 33-42. Retrieved from http://scj.sbu.ac.ir/index.php/SOFEH/article/view/1839

Sajjadzadeh, H. (2011). Group belonging to place, Realization or social residence in traditional neighborhood. BAGH-E-NAZAR journal, 8(16), 17-28. Retrieved from http://www.bagh-sj.com/article_2_1.html

Sharafi, M., Rashdifar, B., \& Barakpour, N. (2009). Public Participation In Preparing Community Development Plans Case Study: Amir-Abad, Golha Neighborhood. Journal of Architecture and Urban Planning, 2(2), 35-55. Retrieved From http://en.journals.sid.ir/viewpaper.aspx?id=253345

Tahouri, N. (2002). poetic silence and eternally making of similarities in Heideger and alexander`s idea. Journal of kheyal, 3, 70-113.

The Historical and Cultural Center of Hamadan. (1993). Housing Development Consulting Engineers of Iran.

\section{Copyrights}

Copyright for this article is retained by the author(s), with first publication rights granted to the journal.

This is an open-access article distributed under the terms and conditions of the Creative Commons Attribution license (http://creativecommons.org/licenses/by/3.0/). 